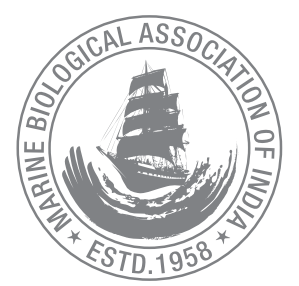

\title{
An assessment of status of marine fishery resources in India through Markov Chain modeling of growth rates in landings
}

\author{
T. V. Sathianandan*, Somy Kuriakose, K.G. Mini, P. K. Safeena and Grinson George \\ ICAR-Central Marine Fisheries Research Institute, Kochi- 682 018, Kerala, India.
}

*Correspondence e-mail: tvsedpl@gmail.com

Received: 13 Nov 2018 Accepted: 25 Jan 2019 Published: 30 Jan 2019

Original Article

\begin{abstract}
The marine fisheries sector in India supports livelihood of four million people and earn a significant amount of foreign exchange through export of marine fish and its products. Historic data showed that the total marine fish production in India maintains an overall upward trend with fluctuations. Periodic assessment of major fishery resource groups is necessary to manage the fishery for sustainability. Among different species groups, 50 commercially important resource groups accounting for about $97 \%$ of the national annual landings were individually studied by Markov Chain modeling of annual growth rates in landings. In addition, the time series data on landings of these marine fishery resource groups were analyzed randomness using 'runs test'. Limiting probabilities for all the nine defined states of each Markov Chain process were determined and status of the resources was derived based on limiting probabilities. Runs test on the time series sequences showed 19 of them having random behavior. It was found through Markov Chain modeling that 16 of the marine fishery resources have probability more than 0.8 to confine their annual growth rate between $-0.25 \%$ and $+0.25 \%$ providing high confidence regarding stable yield from harvest indicating stability of their stocks.
\end{abstract}

Keywords: Marine fish landings, resource assessment, modeling, Markov Chain, runs test, time series data

\section{Introduction}

Marine fisheries in India is a major sector providing livelihood support to nearly four million fisher population. It provides full-time employment to about 0.83 million people and parttime employment to around 0.16 million people of which $93.6 \%$ are associated directly with fishing and $6.4 \%$ are in fishing associated activities Ministry of Agriculture and CMFRI, 2012. The total marine fish production in India has shown steady increase over the last six decades though there were minor dips in between. It has grown from mere 0.5 million tonnes in 1950 to the all time high of 3.94 million tonnes in 2012. The country's export earnings from marine fish products in 2012-13 was 18,856 crores. Compared to the fishery in temperate waters, the diversity of marine 
fishery resources in India is very high keeping the country in an advantageous position preventing major collapses, especially at national level. For example, the catfishes once abundant in southwest coast region of India have drastically the fishery but it continues to be abundant in other regions in more quantities, compensating this loss. It is evident from the species-wise database on landings maintained at the National Marine Fishery Resources Data Centre (NMFDC) of the Central Marine Fisheries Research Institute (CMFRI), the species diversity is so high that there are more than 1200 species of marine fin and shell fishes seen in the fishery along the Indian coast and more than 600 species do exist in the landings every year.

Periodic assessment of status of different marine fishery resources is necessary for deriving and implementing suitable management measures in order to keep the fish stocks at sustainable levels. There are different approaches followed to assess the status of marine fishery resources. The traditional approaches are basically divided into two, one which is less data demanding is based on modeling the biomass dynamics of the fish stock using time series data on fish catch and fishing effort as input. The second approach uses yield prediction models at the final stage after deriving information from other models that describe growth patterns, age and weight relationship, mortalities etc., and it require more data input. Though these methods involve high level computations demanding more time and expertise these are widely accepted methods. A simple and quick method was proposed by Mohamed et al. (2010) to make conclusions about the status of the resources from historic time series data on fish catch. In the present study, an attempt is made to derive and demonstrate a method for grouping a set of marine fishery resources based on Markov Chain modeling of the annual growth rates in landings and calculating the limiting probabilities.

Srinath (1996) examined the impact of introduction of the ring-seine gear in Kerala on the composition of pelagic fish using Markov Chain model and attempted to predict the status of the dominance of the major pelagic groups. Vivekanandan et al. (2002) used Markov Chain model to assess the changes in dominance of four species of threadfin breams over fifteen years in Chennai Fisheries Harbour, Tamil Nadu and found a major shift in the species composition of the threadfin breams based on the steady state probabilities worked out for the model. Mini and Somy (2004) used a four state Markov Chain model to study the changes in landings along the southwest coast of India and predicted decline in landings in this region. Somy and Mini (2006) studied the dynamics of pelagic resource assemblages along the Karnataka coast with reference to change in composition and relative dominance using Markov Chain model and concluded that oil sardine and Indian mackerel are likely to dominate in the fishery along Karnataka coast.

Steel et al. (2001) described movement patterns of hatcheryraised, juvenile, spring chinook salmon, using a two-state Markov Chain model estimating transition probability matrix of the model from travel times within river segments using a method of moments and found changes in duration of stay between rivers. Johnson et al. (2004) carried out a Markov Chain analysis to map fish entertainment zones using data on salmon smolts migrating near the ice/trash sluiceway at the Dalles Dam on the Columbia River. Firdaniza and Gusriani (2018) used Markov Chain model for demersal fish yield analysis in Indonesia's Fisheries Management Area and obtained predictive value of demersal fishing yields by calculating the combination of limiting probability with average catch results below and above the median.

\section{Material and methods}

Time series data on annual landings along the coast of India for 50 commercially important marine fishery resource groups during the period 1985 to 2012 collected from the NMFDC of CMFRI were used for the analysis. Annual growth rates in landings of these resources in each year were first worked out for all the resources as percentages. In order to translate the percentage growth rates in each year into states of a Markov Chain process with nine different states, the rules given in Table 1 were followed. Based on this, for each resource the sequence of movements from one state to another over years during the period from 1985 to 2012 were recorded and used as the basic required data for Markov Chain modeling. The logic behind considering the growth rates in fish landings is that it is not favourable to have very high growth rates in the long run, whether it is positive or negative, for maintaining the harvest at sustainable level. For a fully exploited resource, growth rates fluctuating around zero in the long run is good for sustainability of the resource and advocates maximum

Table 1. Classification of annual growth rates of resources into nine different states for Markov Chain modeling

\begin{tabular}{ll}
\hline $\begin{array}{l}\text { Range for percentage annual growth rate in } \\
\text { landings }\end{array}$ & $\begin{array}{l}\text { Defined state for the Markov } \\
\text { Chain model }\end{array}$ \\
\hline Less than $-100 \%$ & State-1 \\
\hline Between $-100 \%$ and $-50 \%$ & State-2 \\
\hline Between $-50 \%$ and $-25 \%$ & State-3 \\
\hline Between $-25 \%$ and $-1 \%$ & State-4 \\
\hline No growth $(-1 \%$ to $+1 \%)$ & State-5 \\
\hline Between $1 \%$ and $25 \%$ & State-6 \\
\hline Between $25 \%$ and $50 \%$ & State-7 \\
\hline Between $50 \%$ and $100 \%$ & State-8 \\
\hline More than $100 \%$ & State-9 \\
\hline
\end{tabular}


limiting probabilities for stages 4, 5 and 6 when modeled by Markov Chain.

For each of the resources, the sequence of movements from one state to another over years were generated by classifying the annual growth rate in landings into a suitable state as per the definitions in Table 1. The transition probability for a particular transition, say moving from state $i$ to state $j$ denoted by $r_{i j}$ is estimated as the ratio of number of movements from state $I$ to state $j$ to the total number of movements. Accordingly, for each resource we get a transition probability matrix denoted by $R$ of order $9 \times 9$. The following expressions describe the calculation of limiting probabilities for the Markov Chain model which is the expected probability for each of the nine states in the long run.

$R=\left(r_{i j}\right)_{9 \times 9}$ is the transition probability matrix where $r_{i j}$ is the estimated probability for the resource to move from state $i$ to state $j$ for $i, j=1, \cdots, 9$

$E=\left(e_{i j}\right)_{9 \times 9}$ is a matrix with all its elements unity

$\left(e_{i j}=1\right.$ for $\left.i, j=1, \cdots, 9\right)$

$I=\left(a_{i j}\right)_{9 \times 9}$ is the identity matrix $\left(a_{i j}=1\right.$ for $i=j$ and $a_{i j}=0$ for $i \neq j$ )

$P=\left(p_{i 1}\right)_{9 \times 1}$ is a column vector with all its elements unity $\left(p_{i 1}=1\right.$ for $\left.i=1, \cdots, 9\right)$

The limiting probability vector $M=\left(m_{i 1}\right)_{9 \times 1}$ is then computed using the formula

$\left[M=R^{\prime}+E-I\right]^{-1} P$

For each of the resources the limiting probabilities to remain in each one of the nine states were worked out separately using the above procedure.

An initial test of randomness in the landings series of each of the 50 resources were also carried out using 'runs test'. A 'run' is a sequence of 'alike' situation and for this test the criteria used is whether the value is above or below the overall average of the time series sequence. Define $R$ as the number of runs in the time series, $T$ as the size of the time series, $T_{a}$ as the number of values in the time series that are above the overall average and $T_{b}$ as the number of values in the time series that are below the overall average. The test statistic for the 'runs test' is as given below:

$Z=\frac{\left(R-E_{r}\right)}{\sqrt{V_{r}}}$

Z will have a standard normal distribution and can be used for testing the null hypothesis that the time series sequence is a random sequence against a suitable alternative hypothesis. Here $R, E_{r}$ and $V_{r}$ are computed using the formula given below.

$E_{r}=\frac{\left(T+2 T_{a} T_{b}\right)}{T}$ and $V_{r}=\frac{2 T_{a} T_{b}\left(2 T_{a} T_{b}-T\right)}{T^{2}(T-1)}$

\section{Results and discussion}

The time series plot of marine fish landings along the main land of India (in million tonnes) during 1985-2012 is shown in Fig.1. The overall trend of the entire time series is linear upward (slope 0.064 and $R^{2} 0.806$ ) but we can split the period into three. In the initial phase from 1985 to 1997, the marine fish landings grown linearly from 1.52 million tonnes to 2.69 million tonnes (slope 0.0805 and $R^{2} 0.805$ ), in the second phase during 1998 to 2005 it fluctuated around 2.5 million tonnes and in the last phase from 2006 to 2012, it grown from 2.3 million tonnes to 3.94 million tonnes (slope 0.2202 and $R^{2} 0.961$ ).

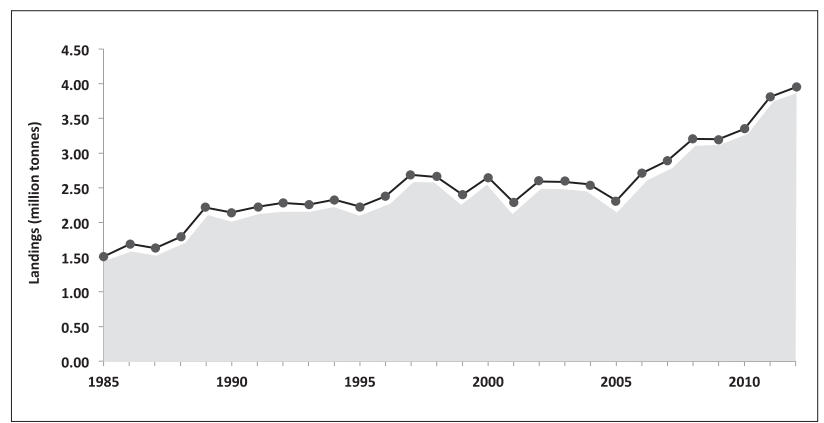

Fig. 1. Marine fish landings in India during 1985 - 2012

Though the overall status of marine fish landings is encouraging, it is wise to examine the individual resource groups separately and assess their status for maintaining sustainability in the marine fisheries sector. As a first step, each of the major 50 resource groups that contribute maximum towards the all India marine fish landings (accounts for $97 \%$ of the landings) were primarily examined through (runs test) and the results are given in Table 2. Out of the 50 resources examined for randomness, 19 were found non-significant in runs test (marked $\mu$ in Table 2) revealing that the landings of these resources behave in a random fashion about their mean, disregarding the quantum of fluctuation from the mean.

For each of the 50 marine fishery resources Markov Chain modeling was carried out using the time series data on annual landings and the limiting probabilities for each Markov Chain to fall in the nine states is given in Table 3. The Markov Chain modeling revealed that there are 29 resource groups for which the limiting probabilities are maximum for states- 6 and state- 4 respectively. Similarly there are 16 resources for which the limiting probabilities are maximum for state- 4 followed by state- 6 . From Table 3 we can make out that the limiting probability for the annual growth rates in landings 
Table 2. Details of runs test carried out for 50 major marine fishery resources

\begin{tabular}{|c|c|c|c|c|c|c|c|}
\hline No. & Species/Group & Average Landings & Landings \% & $\mathrm{R}$ & $\mathrm{T}_{\mathrm{a}}$ & $T_{b}$ & Z \\
\hline 1 & Oil sardine & 535550 & 16.4 & 4 & 12 & 16 & -4.22 \\
\hline 2 & Penaeid prawns $(\mu)$ & 247971 & 7.0 & 10 & 12 & 16 & -1.86 \\
\hline 3 & Indian mackerel & 211740 & 6.4 & 8 & 14 & 14 & -2.70 \\
\hline 4 & Croakers & 200644 & 5.6 & 4 & 15 & 13 & -4.23 \\
\hline 5 & Ribbon fishes & 200644 & 5.8 & 8 & 11 & 17 & -2.57 \\
\hline 6 & Non-penaeid prawns & 167399 & 4.3 & 4 & 15 & 13 & -4.23 \\
\hline 7 & Cephalopods $(\mu)$ & 160621 & 4.7 & 10 & 15 & 13 & -1.91 \\
\hline 8 & Threadfin breams & 154732 & 4.6 & 6 & 11 & 17 & -3.38 \\
\hline 9 & Lesser sardines & 115831 & 3.3 & 8 & 12 & 16 & -2.64 \\
\hline 10 & Bombayduck $(\mu)$ & 111313 & 3.1 & 11 & 17 & 11 & -1.36 \\
\hline 11 & Catfishes & 93526 & 2.4 & 8 & 10 & 18 & -2.46 \\
\hline 12 & Silverbellies & 87578 & 2.7 & 8 & 13 & 15 & -2.68 \\
\hline 13 & Other clupeids & 78982 & 2.2 & 8 & 11 & 17 & -2.57 \\
\hline 14 & Other carangids $(\mu)$ & 75699 & 2.1 & 12 & 13 & 15 & -1.13 \\
\hline 15 & Stolephorus $(\mu)$ & 71665 & 1.9 & 14 & 12 & 16 & -0.28 \\
\hline 16 & Scads $(\mu)$ & 66080 & 2.2 & 12 & 12 & 16 & -1.07 \\
\hline 17 & Lizard fishes & 59129 & 1.7 & 6 & 8 & 20 & -3.06 \\
\hline 18 & Other perches & 59031 & 1.4 & 6 & 12 & 16 & -3.43 \\
\hline 19 & Crabs & 51852 & 1.4 & 6 & 13 & 15 & -3.46 \\
\hline 20 & Soles $(\mu)$ & 50331 & 1.5 & 10 & 14 & 14 & -1.93 \\
\hline 21 & Hilsa shad & 45454 & 1.0 & 9 & 11 & 17 & -2.17 \\
\hline 22 & Thryssa $(\mu)$ & 38437 & 1.1 & 10 & 15 & 13 & -1.91 \\
\hline 23 & Horse mackerel & 33627 & 0.9 & 6 & 13 & 15 & -3.46 \\
\hline 24 & S. commerson & 33012 & 0.9 & 8 & 14 & 14 & -2.70 \\
\hline 25 & Coilia $(\mu)$ & 31637 & 0.9 & 13 & 11 & 17 & -0.55 \\
\hline 26 & Silver pomfret $(\mu)$ & 30019 & 0.8 & 10 & 12 & 16 & -1.86 \\
\hline 27 & Goatfishes & 29422 & 0.9 & 6 & 10 & 18 & -3.31 \\
\hline 28 & E. affinis & 28999 & 0.8 & 8 & 10 & 18 & -2.46 \\
\hline 29 & Stomatopods & 28188 & 0.7 & 3 & 12 & 16 & -4.61 \\
\hline 30 & Rock cods & 26282 & 0.8 & 4 & 14 & 14 & -4.24 \\
\hline 31 & Sharks $(\mu)$ & 26132 & 0.7 & 11 & 11 & 17 & -1.36 \\
\hline 32 & Barracudas & 25293 & 0.8 & 6 & 12 & 16 & -3.43 \\
\hline 33 & Wolf herring & 22031 & 0.6 & 9 & 11 & 17 & -2.17 \\
\hline 34 & Rays $(\mu)$ & 21637 & 0.6 & 10 & 11 & 17 & -1.76 \\
\hline 35 & Black pomfret $(\mu)$ & 19112 & 0.5 & 10 & 12 & 16 & -1.86 \\
\hline 36 & S. guttatus $(\mu)$ & 18086 & 0.4 & 16 & 12 & 16 & 0.51 \\
\hline 37 & Other tunnies & 15287 & 0.4 & 4 & 8 & 20 & -4.01 \\
\hline 38 & Pig-face breams & 13823 & 0.4 & 4 & 18 & 10 & -4.15 \\
\hline 39 & Leather-jackets & 12409 & 0.3 & 3 & 11 & 17 & -4.59 \\
\hline 40 & Setipinna & 11850 & 0.3 & 4 & 10 & 18 & -4.15 \\
\hline 41 & Eels & 11745 & 0.3 & 6 & 13 & 15 & -3.46 \\
\hline 42 & Threadfins $(\mu)$ & 10888 & 0.3 & 11 & 13 & 15 & -1.52 \\
\hline 43 & Big-Jawed Jumper & 10428 & 0.3 & 7 & 12 & 16 & -3.04 \\
\hline 44 & Auxis spp. $(\mu)$ & 10117 & 0.3 & 12 & 13 & 15 & -1.13 \\
\hline 45 & Other shads $(\mu)$ & 9306 & 0.3 & 13 & 15 & 13 & -0.75 \\
\hline 46 & K. pelamis & 8027 & 0.2 & 6 & 9 & 19 & -3.20 \\
\hline 47 & T. tonggol $(\mu)$ & 7989 & 0.3 & 12 & 13 & 15 & -1.13 \\
\hline 48 & Bill fishes & 7977 & 0.2 & 6 & 12 & 16 & -3.43 \\
\hline 49 & Snappers & 7817 & 0.2 & 6 & 12 & 16 & -3.43 \\
\hline 50 & Mullets $(\mu)$ & 7529 & 0.2 & 15 & 11 & 17 & 0.26 \\
\hline
\end{tabular}


T. V. Sathianandan et al.

\begin{tabular}{|c|c|c|c|c|c|c|c|c|c|c|}
\hline \multirow{2}{*}{ SI. No. } & \multirow{2}{*}{ Resource } & State-1 & State-2 & State-3 & State-4 & State- 5 & State- 6 & State-7 & State-8 & State-9 \\
\hline & & $<-100$ & -51 to -100 & -26 to -50 & -1 to -25 & 0 & 1 to 25 & 26 to 50 & 51 to 100 & $>100$ \\
\hline 1 & Oil sardine & 0.000 & 0.038 & 0.112 & 0.264 & 0.000 & 0.277 & 0.136 & 0.092 & 0.080 \\
\hline 2 & Penaeid prawns & 0.000 & 0.000 & 0.000 & 0.304 & 0.119 & 0.534 & 0.043 & 0.000 & 0.000 \\
\hline 3 & Indian mackerel & 0.000 & 0.000 & 0.218 & 0.241 & 0.000 & 0.322 & 0.115 & 0.075 & 0.029 \\
\hline 4 & Croakers & 0.000 & 0.000 & 0.036 & 0.422 & 0.000 & 0.464 & 0.078 & 0.000 & 0.000 \\
\hline 5 & Ribbon fishes & 0.000 & 0.000 & 0.113 & 0.382 & 0.000 & 0.281 & 0.143 & 0.038 & 0.042 \\
\hline 6 & Non-penaeid prawns & 0.000 & 0.034 & 0.000 & 0.393 & 0.044 & 0.236 & 0.226 & 0.067 & 0.000 \\
\hline 7 & Cephalopods & 0.000 & 0.000 & 0.032 & 0.345 & 0.000 & 0.428 & 0.162 & 0.032 & 0.000 \\
\hline 8 & Threadfin breams & 0.000 & 0.000 & 0.014 & 0.349 & 0.000 & 0.404 & 0.233 & 0.000 & 0.014 \\
\hline 9 & Lesser sardine & 0.000 & 0.000 & 0.038 & 0.423 & 0.038 & 0.269 & 0.231 & 0.000 & 0.000 \\
\hline 10 & Bombayduck & 0.000 & 0.000 & 0.048 & 0.429 & 0.000 & 0.444 & 0.044 & 0.044 & 0.000 \\
\hline 11 & Catfishes & 0.000 & 0.000 & 0.000 & 0.490 & 0.000 & 0.433 & 0.077 & 0.000 & 0.000 \\
\hline 12 & Silverbellies & 0.000 & 0.000 & 0.000 & 0.500 & 0.000 & 0.490 & 0.014 & 0.000 & 0.000 \\
\hline 13 & Other clupeids & 0.000 & 0.000 & 0.038 & 0.385 & 0.038 & 0.462 & 0.038 & 0.038 & 0.000 \\
\hline 14 & Other carangids & 0.000 & 0.000 & 0.000 & 0.458 & 0.000 & 0.500 & 0.042 & 0.000 & 0.000 \\
\hline 15 & Stolephorus & 0.000 & 0.000 & 0.196 & 0.407 & 0.000 & 0.150 & 0.113 & 0.134 & 0.000 \\
\hline 16 & Scads & 0.000 & 0.031 & 0.229 & 0.229 & 0.000 & 0.115 & 0.229 & 0.046 & 0.122 \\
\hline 17 & Lizard fishes & 0.000 & 0.000 & 0.080 & 0.361 & 0.000 & 0.433 & 0.000 & 0.129 & 0.000 \\
\hline 18 & Other perches & 0.000 & 0.000 & 0.077 & 0.231 & 0.077 & 0.423 & 0.115 & 0.077 & 0.000 \\
\hline 19 & crabs & 0.000 & 0.000 & 0.036 & 0.435 & 0.000 & 0.348 & 0.109 & 0.072 & 0.000 \\
\hline 20 & Soles & 0.000 & 0.000 & 0.041 & 0.349 & 0.035 & 0.415 & 0.118 & 0.041 & 0.000 \\
\hline 21 & Hilsa shad & 0.000 & 0.115 & 0.115 & 0.192 & 0.000 & 0.192 & 0.154 & 0.192 & 0.038 \\
\hline 22 & Thryssa & 0.000 & 0.000 & 0.115 & 0.313 & 0.000 & 0.458 & 0.038 & 0.076 & 0.000 \\
\hline 23 & Horse Mackerel & 0.000 & 0.000 & 0.067 & 0.356 & 0.000 & 0.356 & 0.133 & 0.067 & 0.022 \\
\hline 24 & S. commerson & 0.000 & 0.000 & 0.038 & 0.423 & 0.000 & 0.385 & 0.154 & 0.000 & 0.000 \\
\hline 25 & Coilia & 0.000 & 0.000 & 0.110 & 0.219 & 0.086 & 0.512 & 0.037 & 0.037 & 0.000 \\
\hline 26 & Silver pomfret & 0.000 & 0.000 & 0.038 & 0.385 & 0.038 & 0.423 & 0.115 & 0.000 & 0.000 \\
\hline 27 & Goatfishes & 0.000 & 0.000 & 0.075 & 0.311 & 0.000 & 0.308 & 0.198 & 0.072 & 0.036 \\
\hline 28 & E. affinis & 0.000 & 0.000 & 0.109 & 0.375 & 0.000 & 0.239 & 0.201 & 0.076 & 0.000 \\
\hline 29 & Stomatopods & 0.000 & 0.000 & 0.132 & 0.413 & 0.033 & 0.298 & 0.124 & 0.000 & 0.000 \\
\hline 30 & Rock cods & 0.000 & 0.000 & 0.033 & 0.233 & 0.000 & 0.458 & 0.167 & 0.108 & 0.000 \\
\hline 31 & Sharks & 0.000 & 0.000 & 0.080 & 0.360 & 0.000 & 0.440 & 0.120 & 0.000 & 0.000 \\
\hline 32 & Barracudas & 0.000 & 0.000 & 0.038 & 0.346 & 0.000 & 0.423 & 0.154 & 0.038 & 0.000 \\
\hline 33 & Wolf herring & 0.000 & 0.000 & 0.038 & 0.423 & 0.038 & 0.423 & 0.038 & 0.038 & 0.000 \\
\hline 34 & Rays & 0.000 & 0.000 & 0.044 & 0.436 & 0.000 & 0.441 & 0.079 & 0.000 & 0.000 \\
\hline 35 & Black pomfret & 0.000 & 0.000 & 0.113 & 0.222 & 0.115 & 0.354 & 0.195 & 0.000 & 0.000 \\
\hline 36 & S. guttatus & 0.000 & 0.000 & 0.159 & 0.325 & 0.000 & 0.369 & 0.032 & 0.115 & 0.000 \\
\hline 37 & Other tunnies & 0.000 & 0.070 & 0.284 & 0.082 & 0.000 & 0.123 & 0.167 & 0.170 & 0.105 \\
\hline 38 & Pig-face breams & 0.000 & 0.038 & 0.038 & 0.269 & 0.038 & 0.385 & 0.115 & 0.077 & 0.038 \\
\hline 39 & Leather-jackets & 0.000 & 0.000 & 0.040 & 0.439 & 0.000 & 0.321 & 0.160 & 0.040 & 0.000 \\
\hline 40 & Setipinna & 0.000 & 0.000 & 0.185 & 0.269 & 0.000 & 0.308 & 0.077 & 0.115 & 0.046 \\
\hline 41 & Eels & 0.000 & 0.000 & 0.037 & 0.407 & 0.000 & 0.481 & 0.074 & 0.000 & 0.000 \\
\hline 42 & Threadfins & 0.000 & 0.000 & 0.113 & 0.274 & 0.034 & 0.377 & 0.164 & 0.038 & 0.000 \\
\hline 43 & Big-jawed jumber & 0.000 & 0.000 & 0.153 & 0.376 & 0.038 & 0.264 & 0.099 & 0.071 & 0.000 \\
\hline 44 & Auxis. spp & 0.000 & 0.068 & 0.098 & 0.352 & 0.000 & 0.249 & 0.121 & 0.000 & 0.112 \\
\hline 45 & Other shads & 0.000 & 0.036 & 0.269 & 0.209 & 0.000 & 0.142 & 0.155 & 0.107 & 0.083 \\
\hline 46 & K. pelamis & 0.000 & 0.141 & 0.192 & 0.125 & 0.000 & 0.034 & 0.090 & 0.115 & 0.303 \\
\hline 47 & T. tonggol & 0.000 & 0.000 & 0.253 & 0.182 & 0.000 & 0.160 & 0.180 & 0.157 & 0.068 \\
\hline 48 & Bill fishes & 0.000 & 0.000 & 0.038 & 0.346 & 0.000 & 0.423 & 0.154 & 0.038 & 0.000 \\
\hline 49 & Snappers & 0.000 & 0.000 & 0.077 & 0.310 & 0.000 & 0.545 & 0.026 & 0.042 & 0.000 \\
\hline 50 & Mullets & 0.000 & 0.038 & 0.115 & 0.385 & 0.000 & 0.154 & 0.154 & 0.115 & 0.038 \\
\hline
\end{tabular}


to remain between $-25 \%$ and $+25 \%$ (states $4,5,6$ ) is higher than 0.9 in the case of four resources namely Penaeid prawns, Catfishes, Silverbellies and Other carangids. This probability is between 0.8 and 0.9 for 12 resources, between 0.7 and 0.8 for 12 resources, between 0.6 and 0.7 for 9 resources and between 0.5 and 0.6 for 5 resources leaving only 8 resources to have less than 0.5 probability to fall in states $4,5,6$. The limiting probabilities for state- 4 and state- 6 of those resources having more than 0.8 limiting probability for states 4, 5, 6 are shown in Fig. 2. Among the four resources with more than 0.9 limiting probability to fall in states $4,5,6$ the three resources have almost equal limiting probabilities to fall in state- 4 and state- 6 are Silverbellies $(0.50 \& 0.49)$, catfishes (0.49\& 0.43$)$ and Other carangids ( $0.46 \& 0.50)$. In the group of 12 resources having limiting probabilities between 0.8 and 0.9 for the states $4,5,6$ those with almost equal limiting probabilities for state- 4 and state- 6 are Wolf herring $(0.42,0.42)$, S. commerson $(0.42 \& 0.39)$, Croakers (0.42 \& 0.46), Rays ( $0.44 \& 0.44)$, Bombayduck ( $0.43 \& 0.44)$ and Silver pomfret $(0.39 \& 0.42)$.

The above results indicate that the growth rates in annual landings are most likely to confine between $-25 \%$ and $+25 \%$ with equal chance to fall on both sides for the fishery resources such as Silverbellies, Catfishes, Other carangids, Wolf herring, S. commerson, Croakers, Rays, Bombayduck and Silver pomfret. Thus, there should not be any concern about the stability of these nine fish stocks and we can expect steady yield with limited fluctuation over the years.

In the list of marine fishery resources in Table 2 the first five resources namely Oil sardine, Penaeid prawns, Indian mackerel, Croakers and Ribbon fishes contribute nearly 25\% to the total landings. Results of the 'runs test' for Penaeid prawns landings describes its time series as fluctuating

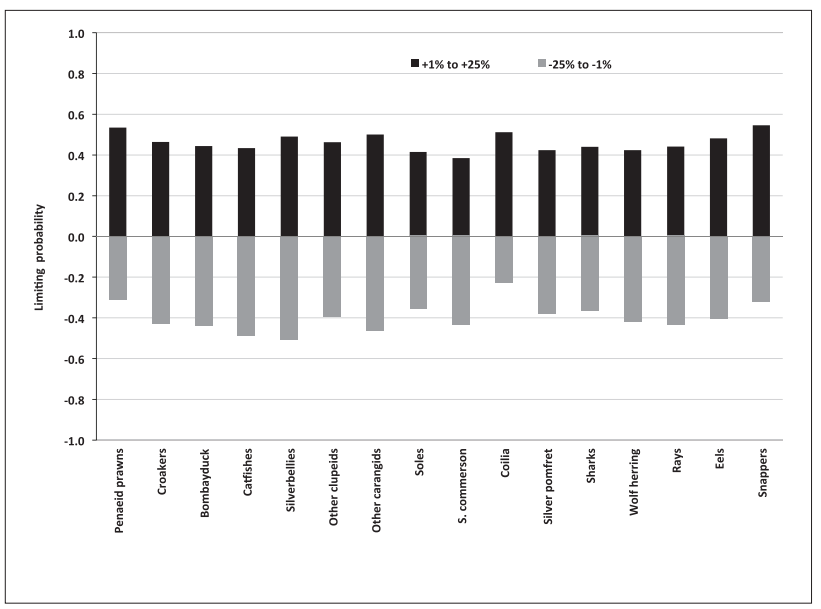

Fig. 2. Plot of limiting probabilities of resources with high values for state-4 $(-25 \%$ to $-1 \%)$ and state- $6(+1 \%$ to $+25 \%)$. randomly about its mean without revealing the extent of fluctuation. The limiting probabilities computed for the nine states of the Markov Chain model corresponding to this resource tells that it has limiting probabilities $0.534,0.304$ and 0.119 to stay in state- 6 , state- 4 and state- 5 respectively. Thus the probability that the growth rates in annual landings of Penaeid prawns will fall beyond the range $-25 \%$ and $+25 \%$ in the long run is only 0.043 showing high confidence about the stability in its landings around the average of 2.48 lakh tonnes (probability that in future the landings of Penaeid prawns lies between 1.86 and 3.10 is as high as 0.957 ). It may be noted that among all the resources this resource has maximum limiting probability of 0.119 for state- 5 (annual growth rate is extremely less, between $-1 \%$ and $+1 \%$ only) and state- 6 has higher limiting probability than state- 4 indicating higher chance to have positive growth in the long run. Thus, we may expect slightly higher yield than the current average yield in the case of Penaed prawns. Other resources with a similar behavior are Soles, Coilia, Sharks, Eels, Snappers and Other clupeids.

In the case of Oil sardine, the major single species resource with average contribution of $16.4 \%$, the runs test of randomness was significant indicating that the time series on landings of Oil sardine does not have any random behavior. The Markov Chain model fitted for oil sardine describing the dynamics of annual growth pattern in its landings revealed that the limiting probabilities were confined mainly to states 3 to 7 indicating that the probability to lie the annual growth rates in its landings between $-50 \%$ and $+50 \%$ in the long run is as high as 0.789 . Further, the probability to fluctuate the annual growth rates within $-25 \%$ and $+25 \%$ is 0.540 and the aggregate limiting probabilities for $+v e$ and -ve growth rates are 0.59 and 0.41 respectively. Hence, what we can expect in the case of Oil sardine landings is to have high fluctuations with slightly higher chance for increase in landings.

Indian mackerel is the resource with third highest contribution of $6.4 \%$ towards total landings, which is also a single species resource. This resource also does not show random behavior as per the runs test applied to the time series of its landings. Limiting probabilities worked out for the 9 states of the Markov Chain fitted to annual growths in landings shows that in the long run the annual growth rates will fluctuate between - $50 \%$ and $+50 \%$ with probability 0.896 and further this will confine to $-25 \%$ and $+25 \%$ with probability 0.563 . The aggregate of limiting probabilities for the annual growth rates in landings of this resource to fall in states $1,2,3$ is 0.22 ; to fall in states $4,5,6$ is 0.56 and to fall in states $7,8,9$ is 0.22 indicating that there is high probability $(0.44)$ to have fluctuations in the long run with more than $25 \%$ growth both positive and negative. 
The overall limiting probabilities for negative and positive growth rates in annual landings of Indian mackerel are 0.459 and 0.551 respectively. Thus Indian mackerel has almost similar expectations to that of oil sardine regarding behavior in landings disregarding the time.

The fourth most contributing resources is ribbon fishes with a contribution of $5.8 \%$ towards total landings and the fifth is croakers with $5.6 \%$. Ribbon fishes have maximum limiting probabilities for the growth rates to fall between $-50 \%$ and $+50 \%$ which is 0.919 . In case of croakers, the limiting probability for the annual growth rates to fall within $-25 \%$ and $+25 \%$ is maximum.

There are 11 resources with limiting probabilities less than 0.05 to fall their growth rates in states other than 4,5 and 6 namely Penaeid prawns, Croakers, Bombayduck, Catfishes, Silver bellies, Other clupeids, Other carangids, Wolf herring, Rays, Eels and Snappers. Similarly Scads, Auxis spp., other Tunnies and $K$. pelamis have significant limiting probabilities for their growth rates to fall beyond $100 \%$ (state- 9 ).

Srinath (2003), after an appraisal of marine fish landings during the different decadal periods since 1961, indicated the growth rates as $9.4,3.2,10.7$ and $0.7 \%$. The growth during the latest phase is indicative of the true state of the fishery. Mohamed et al. (2010) analyzed catch data of a total of 19 species in Kerala and 22 species in Karnataka were analysed and found that nearly $37 \%$ of the species considered in Kerala were in abundant or less abundant status and $47 \%$ were in declining status. In Karnataka, $32 \%$ of the stocks studied were in healthy status and $55 \%$ were in declining status.

Sathianandan et al. (2011) examined the dynamic changes in the all India landings of 26 major marine fishery resource groups and classified their status as per the approach proposed by Mohamed et al. (2010) using historic time series data on landings. They found that among the 26 fishery resources examined 18 are abundant, 5 less abundant and one each declining, depleted and collapsed respectively. All the important resource groups fall either under 'abundant' or 'less abundant' class. The groups classified under 'less abundant' are elasmobranchs, threadfins, ribbon fishes, mullets and flat fishes. White fish falls under 'declining' flying fishes under 'depleted' and unicorn cod under 'collapsed' class.
As an aid to management, models are used to assess fish populations and the effects of exploitation on them. The current model to assess the status of the stocks is broadly consistent with other studies that have attempted to provide a general picture of fishery status. The present approach offers a framework for assessing the status of the fishery and can be used to examine the dynamics and stability of fish stock when subjected to different exploitation policies. Also, as the approach is based on time series of catch data alone it is highly useful in data limited situations.

\section{Acknowledgements}

The authors thank the Director, Central Marine Fisheries Research Institute for providing necessary facilities for the conduct of this study and for his inspiration and guidelines.

\section{References}

Firdaniza and N. Gusriani. 2018. Markov Chain model for demersal fish catch analysis in Indonesia, IOP Conf. Ser.: Mater. Sci. Eng., 332 doi:10.1088/1757$899 \times / 332 / 1 / 012022$

Formacion and S. B. Saila. 1994. Markov Chain properties related to temporal dominance changes in a Philippine pelagic fishery. Fish. Res., 19(3-4): 241-256.

Jhonson, G. E., J. B. Hedgepeth, J. R. Skalski and A. E. Giorgi. 2004. A Markov Chain analysis of fish movements to determine entrainment zones. Fish. Res., 69: 349-358.

Mini, K. G. and Somy Kuriakose. 2004. Long term projection of the marine fish landings along southwest coast of India using Markov Chain model. J. Mar. Biol. Ass. India, 46 (2): $209-214$

Ministry of Agriculture, Krishi Bhavan, New Delhi and CMFRI, Kochi. 2012. Marine Fisheries Census 2010 Part I India. CMFRl; Kochi. 98pp.

Mohamed, K. S., T. V. Sathianandan, P. U. Zacharia, P. K. Asokan, P. K. Krishnakumar, K. P. Abdurahiman, S. Veena Shettigar and N. Raveendra Durgekar. 2010. Depleted and collapsed marine fish stocks along south-west coast of India - a simple criterion to assess the status. In: Meenakumari, B., Boopendranath, M. R., Leela Edwin, Sankar, T. V., Nikita Gopal and Ninan, G. (Eds.), Coastal fishery resources of India; conservation and sustainable utilisation. Society of Fisheries Technologists, Cochin, p. 67-76.

Sathianandan, T. V., J. Jayasankar, Somy Kuriakose, K. G. Mini and Wilson T. Mathew. 2011. Indian marine fishery resources: optimistic present, challenging future. Indian J. Fish., 58(4): 1-15.

Somy Kuriakose and K. G. Mini. 2006. A stochastic model to analyse pelagic fishery resource dominance along the Karnataka coast. Indian J. Mar. Sci., 35(3): 257262.

Srinath, M. 2003. An appraisal of the exploited marine fishery resources of India. In: M. Mohan Joseph and A. A. Jayaprakash (Eds.) Status of exploited marine fishery resources of India. Central Marine Fisheries Research Institute, Kochi, India. p. 254-285.

Srinath, M. 1996. Markov Chain application to the dynamics of the pelagic fishery along the Kerala coast, India. Indian J. Fish., 43(2): 115-120.

Steel, E. A., P. Guttorp, J. J. Anderson and D. C. Caccia. 2001. Modeling Juvenile Salmon Migration Using a Simple Markov Chain, J. Agric. Biol. Environ Stat., 6(1): 80-88.

Vivekanandan, E., R. Venugopalan and P. Ramadoss. 2002. Assessment of changes in the threadfin bream species composition using Markov Chain, Indian J. Fish, 49(3): 241-245. 